\title{
Drug priming enhances radiosensitivity of adamantinomatous craniopharyngioma via downregulation of survivin
}

\author{
Christina Stache, PhD, ${ }^{1,2}$ Christiane Bils, BSc, ${ }^{1}$ Rudolf Fahlbusch, MD, PhD, ${ }^{3}$ \\ Jörg Flitsch, MD, PhD, ${ }^{4}$ Michael Buchfelder, MD, PhD, ${ }^{5}$ Harald Stefanits, MD, ${ }^{6}$ \\ Thomas Czech, MD, PhD, ${ }^{6}$ Udo Gaipl, PhD, ${ }^{7}$ Benjamin Frey, PhD, ${ }^{7}$ Rolf Buslei, MD, PhD, ${ }^{1}$ and \\ Annett Hölsken, $\mathrm{PhD}^{1}$
}

\begin{abstract}
1Department of Neuropathology, Universitätsklinikum Erlangen, Friedrich-Alexander-Universität Erlangen-Nürnberg, Erlangen, Germany; ${ }^{2}$ Institute of Child Health, University College London, United Kingdom; ${ }^{3}$ International Neuroscience Institute, Hannover, Germany; ${ }^{4}$ Department of Neurosurgery, University Hospital Hamburg-Eppendorf, Hamburg, Germany; ${ }^{5}$ Department of Neurosurgery, University Hospital Erlangen-Nuremberg, Erlangen, Germany; ${ }^{6}$ Department of Neurosurgery, Medical University of Vienna, Austria; and 'Department of Radiation Oncology, Universitätsklinikum Erlangen, Friedrich-Alexander-Universität Erlangen-Nürnberg, Erlangen, Germany
\end{abstract}

OBJECTIVE In this study, the authors investigated the underlying mechanisms responsible for high tumor recurrence rates of adamantinomatous craniopharyngioma (ACP) after radiotherapy and developed new targeted treatment protocols to minimize recurrence. ACPs are characterized by the activation of the receptor tyrosine kinase epidermal growth factor receptor (EGFR), known to mediate radioresistance in various tumor entities. The impact of tyrosine kinase inhibitors (TKIs) gefitinib or CUDC-101 on radiation-induced cell death and associated regulation of survivin gene expression was evaluated.

METHODS The hypothesis that activated EGFR promotes radioresistance in ACP was investigated in vitro using human primary cell cultures of ACP ( $n=10)$. The effects of radiation (12 Gy) and combined radiochemotherapy on radiosensitivity were assessed via cell death analysis using flow cytometry. Changes in target gene expression were analyzed by quantitative real-time polymerase chain reaction (qRT-PCR). Survivin, identified in qRT-PCR to be involved in radioresistance of ACP, was manipulated by small interfering RNA (siRNA), followed by proliferation and vitality assays to further clarify its role in ACP biology. Immunohistochemically, survivin expression was assessed in patient tumors used for primary cell cultures.

RESULTS In primary human ACP cultures, activation of EGFR resulted in significantly reduced cell death levels after radiotherapy. Treatment with TKIs alone and in combination with radiotherapy increased cell death response remarkably, assessed by flow cytometry. CUDC-101 was significantly more effective than gefitinib. The authors identified regulation of survivin expression after therapeutic intervention as the underlying molecular mechanism of radioresistance in ACP. EGFR activation promoting ACP cell survival and proliferation in vitro is consistent with enhanced survivin gene expression shown by qRT-PCR. TKI treatment, as well as the combination with radiotherapy, reduced survivin levels in vitro. Accordingly, ACP showed reduced cell viability and proliferation after survivin downregulation by siRNA.

CONCLUSIONS These results indicate an impact of EGFR signaling on radioresistance in ACP. Inhibition of EGFR activity by means of TKI treatment acts as a radiosensitizer on ACP tumor cells, leading to increased cell death. Additionally, the results emphasize the antiapoptotic and pro-proliferative role of survivin in ACP biology and its regulation by EGFR signaling. The suppression of survivin by treatment with TKI and combined radiotherapy represents a new promising treatment strategy that will be further assessed in in vivo models of ACP.

https://thejns.org/doi/abs/10.3171/2016.9.FOCUS16316

KEY WORDS adamantinomatous craniopharyngioma; radiation; survivin; EGFR; tyrosine kinase inhibitor

ABBREVIATIONS ACP = adamantinomatous craniopharyngioma; $A x V=$ Annexin V; EGF = epidermal growth factor; EGFR = EGF receptor; FITC = fluorescein isothiocyanate; GAPDH = glyceraldehyde 3-phosphate dehydrogenase; HDAC = histone deacetylase; HER2 = human epidermal growth factor receptor 2; PI = propidium iodide; qRT$\mathrm{PCR}$ = quantitative real-time polymerase chain reaction; siRNA = small interfering RNA; TKI = tyrosine kinase inhibitor.

SUBMITTED July 31, 2016. ACCEPTED September 15, 2016

INCLUDE WHEN CITING DOI: 10.3171/2016.9.FOCUS16316. 


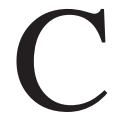
RANIOPHARYNGIOMAS are benign, epithelial tumors of the sellar region in the brain. Posing great difficulties in treatment, adamantinomatous craniopharyngiomas (ACPs) occur during childhood as well as in adult patients and are characterized by activating mutations in the $\beta$-catenin encoding gene CTNNB1. Due to their intricate localization, these tumors often affect crucial surrounding brain structures such as the pituitary, hypothalamus, and optic chiasm, resulting in endocrinological disorder and visual impairment. ${ }^{8,14}$ Treatment is challenging as radical resection poses the risk of damaging crucial brain structures. ${ }^{8,31,46}$ Macroscopic or microscopic tumor residues, which lead to recurrence without further intervention, are treated by postoperative radiation therapy ${ }^{15,28}$ However, subtotal resection and subsequent radiotherapy still result in frequent progressions and recurrences. ${ }^{48}$ While radiotherapy in general is detrimental for the developing brain, brain irradiation during childhood can result in hypopituitarism, requiring lifelong hormone substitution therapy. ${ }^{32}$

We investigated a new adjuvant chemotherapeutic treatment option by studying the impact of epidermal growth factor receptor (EGFR) signaling. Activation of the EGFR and its nuclear translocation has been identified in ACP cluster cells, ${ }^{23}$ and is known to promote radioresistance. ${ }^{7}$ Activation of the EGFR is directly involved in ACP cell motility, which can be inhibited by treatment with the receptor tyrosine kinase inhibitor (TKI) gefitinib. ${ }^{23}$ This drug is clinically approved for treatment of non-small cell lung cancer and blocks activation of the EGFR. ${ }^{5}$ The indicated use of gefitinib is directed toward tumors harboring EGFR mutations. While ACPs show enhanced phosphorylation of the receptor, promoting tumor cell migration, they do not carry EGFR mutations..$^{21,23}$ The nuclear occurrence of activated EGFR is associated with radioresistance in various cancers and is suspected to promote tumor recurrence after radiation therapy. Radiation-induced translocation of the membrane-bound receptor to the nucleus affects DNA repair and therefore enhances radioresistance, ${ }^{7}$ which can be overcome by treatment with TKIs. Research on glioma cell lines was able to demonstrate restored radiosensitivity after combined treatment with radiotherapy and TKI. ${ }^{52}$ A clinical phase II study revealed promising results of a combined gefitinib treatment strategy in childhood brainstem glioma. ${ }^{55}$ Another promising group of agents are histone deacetylase (HDAC) inhibitors, described as radiosensitizers in esophageal cancer and prostate carcinoma, potentially acting via intrinsic apoptosis. ${ }^{13,71}$ CUDC-101 is a combined inhibitor, blocking HDACs, human epidermal growth factor receptor 2 (HER2), and EGFR signaling simultaneously. In vitro assays revealed antiproliferative and proapoptotic effects of CUDC-101, even in cells that were demonstrated to be resistant against single target therapeutics. ${ }^{38}$

Inhibition of EGFR activation in glioma resulted in improved radiosensitivity and enhanced apoptotic cell death. ${ }^{11,17}$ During this process, the protein survivin could be identified as a key component. ${ }^{51}$ Since its first description in $1997,{ }^{4}$ survivin was found to be highly expressed in various cancers such as neuroblastoma, ${ }^{1}$ colorectal cancer, ${ }^{33}$ high-grade lymphoma, ${ }^{4}$ and gastric carcinoma, ${ }^{41}$ suggesting a pathological role of the protein. Described as a nodal protein, survivin interacts with 3 homeostatic networks: control of mitosis, suppression of apoptosis, and cellular stress response. ${ }^{3}$ Survivin expression is active during fetal development, but the protein is rarely expressed in healthy adult tissue; it enhances tumor progression and resistance to apoptotic stimuli in malignancies. ${ }^{45}$ In proliferating cells, survivin can be phosphorylated through cyclin dependent kinase 1, resulting in stabilized survivin and repressed cell death consequently. ${ }^{50}$ The $15 \mathrm{kD}$ protein encoded by BIRC 5 showed an inverse correlation with radiation-induced apoptosis in colon carcinoma. ${ }^{58}$ Survivin acts antiapoptotically, promotes cell proliferation, and contributes to radioresistance benefitting the survival of tumor cells. ${ }^{3}$ It has recently been described to be related to recurrence in craniopharyngioma, promoting tumor cell survival. ${ }^{73}$

In this study we analyzed the mechanisms leading to high tumor recurrence rates of ACP after radiotherapy to optimize treatment outcome for patients with ACP. We aim to demonstrate that radioresistance is promoted by EGFR activation and clarify whether radiosensitivity can be restored by means of TKI treatment. In this context we analyzed the regulation of survivin gene expression in $\mathrm{ACP}$ and its impact on cell death induction after specific gene expression knockdown.

\section{Methods}

\section{Patient Samples}

Fresh craniopharyngioma tissue (Table 1) was obtained from the International Neuroscience Institute Hannover as well as the Departments of Neurosurgery at the University Hospital Erlangen-Nürnberg, University Hospital Hamburg-Eppendorf, and Medical University Vienna. Tumors were diagnosed according to the WHO guidelines for brain tumors ${ }^{40}$ as well as by means of their genomic hallmarks, as previously described. ${ }^{25,62}$ Tumor content was assessed via $\mathrm{H} \& \mathrm{E}$ staining as well as immunohistochemistry (pan-cytokeratin, $\beta$-catenin). All samples were routinely sequenced for mutations in $C T N N B 1$ exon 3 and $B R A F$ V600E. Consent was obtained from every patient for research use of the material. The scientific evaluation of patient samples was approved by the local ethics committee of the University Erlangen-Nürnberg. All analyses were performed according to the Declaration of Helsinki. Fresh tumor tissue was used for primary cell cultures and subsequent extraction of RNA and protein. All cases were anonymized according to the data protection directive.

\section{Immunohistochemical Analysis}

Resected tumor tissue was processed as previously described. ${ }^{9}$ Immunohistochemical analysis was performed automatically on a Ventana BenchMark ULTRA using the iView 3,3'-diaminobenzidine detection kit (Ventana), according to the manufacturer's instructions. Survivin was detected with a rabbit antibody from Abcam (ab24479; survivin clone SP79) in a dilution of 1:100. Histological evaluation was performed on an Olympus BX51 microscope and documented by means of the analySIS software (Soft Imaging Systems GmbH). 
TABLE 1. Summary of patient data under study

\begin{tabular}{lcll}
\hline & Age (yrs), & \multicolumn{2}{c}{ Mutational Analysis } \\
\cline { 3 - 4 } Case $^{*}$ & Sex & \multicolumn{1}{c}{ CTNNB1 Exon 3 } & BRAF V600E \\
\hline ACP1 & $6, \mathrm{M}$ & Codon 37/ Ser>Cys & Not analyzed \\
\hline ACP2 & $14, \mathrm{~F}$ & Not analyzed & Not analyzed \\
\hline ACP3 & $48, \mathrm{M}$ & Codon 32/ Asp>Tyr & Wild type \\
\hline ACP4 & $9, \mathrm{M}$ & Codon 33/ Ser>Phe & Wild type \\
\hline ACP5 & $40, \mathrm{M}$ & Codon 33/ Ser>Cys & Wild type \\
\hline ACP6 & $45, \mathrm{M}$ & Codon 41/ Thr>lle & Wild type \\
\hline ACP7 & $39, \mathrm{M}$ & Codon 33/ Ser>Cys & Wild type \\
\hline ACP8 & $16, \mathrm{~F}$ & Codon 32/ Asp>Asn & Wild type \\
\hline ACP9 & $53, \mathrm{~F}$ & Codon 33/ Ser>Cys & Wild type \\
\hline ACP10 & $28, \mathrm{~F}$ & Not analyzed & Not analyzed \\
\hline
\end{tabular}

* List of patient ACP samples, provided by collaborating neurosurgery departments, used for generation of primary cell cultures. Age represents the age of the patient at the time of tumor surgery. Samples were screened for CTNNB1 and BRAF mutations.

\section{Cell Culture}

Primary ACP cultures were generated from representative tumor samples as previously described. ${ }^{24}$ Surgically removed tissue was immediately processed via instantaneous sections to confirm the diagnosis and tumor cell content before being transferred to tissue culture. All procedures were performed under laminar airflow hoods. Incubation took place at $37^{\circ} \mathrm{C}$ in $5 \% \mathrm{CO}_{2}$ and $95 \%$ relative humidity. A special craniopharyngioma medium ${ }^{66}$ contained DMEM (Gibco) and DMEM + F12 (Gibco; DMEM:F12 final ratio = 3:1), supplemented with L-glutamine (2 mM; Gibco), 10\% fetal bovine serum albumin (Biochrom), $1 \%$ penicillin streptomycin (PenStrep; Gibco), insulin (5 $\mu \mathrm{g} / \mathrm{ml}$; Sigma), transferrin ( $5 \mu \mathrm{g} / \mathrm{ml}$; Millipore), hydrocortisone $(0.4 \mu \mathrm{g} / \mathrm{ml}$; MP Biomedicals), triiodothyronine $\left(2 \times 10^{-9} \mathrm{~mol} / \mathrm{L}\right.$; Sigma $)$, and cholera toxin $\left(2 \times 10^{-10}\right.$ $\mathrm{mol} / \mathrm{L}$; Sigma). Growth was promoted by the addition of epidermal growth factor (EGF; $10 \mathrm{ng} / \mathrm{ml}$, Sigma). Dissociation was performed with Accutase (PAA). Epithelial differentiation was confirmed immunohistochemically by means of pan-cytokeratin antibody staining (1:40, K1-1; Beckman Coulter) on cytospins of early passages.

\section{Combined Radiochemotherapy With CUDC-101 or Gefitinib}

Treatment was performed on 3 subsequent days, while cells underwent irradiation twice a day with 2 Gy per fraction, 8 hours apart (GE Inspection Technologies). The final accumulated dose was $12 \mathrm{~Gy}$ for irradiated samples. The combined radiochemotherapy cells were treated with $0.5 \mathrm{mM}$ CUDC-101 (Sigma) or $0.5 \mathrm{mM}$ gefitinib (selleckchem.com), and $10 \mathrm{ng} / \mathrm{ml}$ EGF daily (Sigma). Mock controls were treated with vehicle (dimethyl sulfoxide) only or $10 \mathrm{ng} / \mathrm{ml}$ EGF. Twenty-four hours after the last irradiation procedure cells were harvested, including supernatant, and used for flow cytometry and RNA extraction.

\section{Transfection of Primary ACP Cell Cultures With Survivin siRNA}

Inhibition of survivin was achieved by using $20 \mathrm{nM}$ validated silencer select pre-designed small interfering RNA (siRNA; BIRC5, Ambion). Cells were incubated in medium without antibiotics up to a confluency of $40 \%$. Lipofectamine 3000 (Invitrogen) or lipofectamine RNAiMAX (Invitrogen) was used to transfect cells in serum-free medium. Transfection with Silencer Select Negative Control No. 1 siRNA (Ambion) was performed in mock-treated controls. Inhibition of survivin was assessed by quantitative real-time polymerase chain reaction (qRT-PCR).

\section{Quantitative Real-Time Polymerase Chain Reaction}

Total RNA was extracted from primary ACP cultures with TRIzol according to the manufacturer's instructions (Invitrogen). After DNA digestion (DNAse I, Invitrogen), reverse transcription was performed with the SuperScript First-Strand Synthesis System (Invitrogen) and oligo-dT primers. qRT-PCR was conducted on an Applied Biosystems 7500 Fast RT-PCR system. Glyceraldehyde 3-phosphate dehydrogenase (GAPDH) served as a reference gene. Analyses were carried out in triplicate. To assess specific amplification, controls without cDNA were included and a melting curve analysis was performed after each experiment. Specific mRNA primer sequences for detection of gene expression in qRT-PCR are listed in Table 2. For quantification of readings we used the comparative cycle threshold method according to the manufacturer's instructions.

\section{Cell Death Analysis With Annexin V/Propidium lodide Staining in Flow Cytometry}

Discrimination between viable and dead cells was achieved by Annexin V/propidium iodide (PI) staining and flow cytometry on a Beckman Coulter Gallios. Fluorescein isothiocyanate (FITC)-labeled Annexin V (AxVFITC) binds phosphatidylserine exposed on the outer cell membrane of apoptotic cells, due to their disrupted metabolism. ${ }^{37,67}$ The fluorophore PI labels necrotic but not apoptotic cells where it can not enter the cell due to its intact cell membrane. ${ }^{12,49}$ For flow cytometry, $2 \times 10^{5}$ cells were labeled with $400 \mu \mathrm{l}$ of AxV/PI mix $(1 \mu \mathrm{g} / \mathrm{ml} \mathrm{AxV-FITC \text {, }}$ $20 \mu \mathrm{g} / \mathrm{ml}$ PI). Each sample was analyzed in triplicate. Data analysis was performed with Kaluza software (Beckman Coulter).

TABLE 2. Specific mRNA primer for qRT-PCR

\begin{tabular}{cllc}
\hline Gene & \multicolumn{1}{c}{ Forward Primer 5'-3' } & \multicolumn{1}{c}{ Reverse Primer 3'-5' } & Fragment Length (bp) \\
\hline GAPDH & CAACGACCACTTTGTCAAGC & CCTGTTGCTGTAGCCAAATTC & $166 / 61$ \\
\hline Survivin & ACCGCATCTCTACATTCAAG & CAAGTCTGGCTCGTTCTC & 113 \\
\hline
\end{tabular}




\section{Proliferation Assay}

Cell proliferation was measured in a colorimetric assay with the enzyme-linked immunosorbent assay-BrdU kit (Roche). The pyrimidine analog BrdU (5-bromo2-desoxyuridine) is integrated in newly synthesized DNA instead of thymidine during cell division and can be detected by horseradish peroxidase-labeled antibodies. Conversion of a chemiluminescence substrate and emission of light can be measured photometrically (Sunrise, Tecan; $\lambda$ $=370 \mathrm{~nm}$, reference wavelength $\lambda=492 \mathrm{~nm}$ ) and is proportional to the number of dividing cells. The addition of $1 \mathrm{M} \mathrm{H}_{2} \mathrm{SO}_{4}$ stops the reaction and color change can be measured at $\lambda=450 \mathrm{~nm}$ (reference wavelength $\lambda=690$ $\mathrm{nm})$. Every sample was analyzed as a biological sextuplet in a 96-well plate. Results were analyzed with XFluor4 software (Tecan).

\section{Cell Viability Assay}

MTT (3-[4,5-dimethylthiazol-2-yl]-2,5-diphenyltetrazolium bromide; Sigma) is a colorimetric assay used to evaluate cell viability. The level of endogenous nicotinamide adenine dinucleotide diphosphate-dependent oxidoreductases indicates the number of viable cells, as it catalyzes the reduction of yellow tetrazolium dye MTT into purple, insoluble formazan. Every sample was analyzed as a biological sextuplet in a 96-well plate. Color intensity was measured photometrically (Sunrise, Tecan) at $\lambda=550$ $\mathrm{nm}$ with a reference wavelength of $\lambda=690 \mathrm{~nm}$. Results were analyzed with the XFluor4 software.

\section{Statistics}

A Kolmogorov-Smirnov normality test followed by a Wilcoxon signed-rank test, Wilcoxon matched-pairs signed-rank test, or Mann-Whitney U-test was performed where appropriate using GraphPad Prism (version 6.00 for Windows, GraphPad Software). A p value $\leq 0.05$ was considered statistically significant.

\section{Results}

\section{EGFR Activation and Radioresistance in Primary ACP Tumor Cells}

To our knowledge, no radiotherapy experiments on primary ACP cell cultures have been published so far. As a guideline for our study we used the radiotherapy protocol performed clinically on human ACP, where fractions of a maximum of 2 Gy are applied to avoid neurotoxicity and damage of radiosensitive, healthy brain tissue. ${ }^{32} \mathrm{Ra}-$ diation applied to the brain generally ranges between 50 and $60 \mathrm{~Gy}$; higher doses are more likely to induce necrosis and radiation-induced secondary tumors. ${ }^{19,28,31}$ We tested fractionated radiotherapy with single fractions of $2 \mathrm{~Gy}$ until a significant effect on ACP cells was detected. To reveal the impact of EGFR activation on radiosensitivity we analyzed primary ACP cultures after EGF treatment and subsequent radiotherapy. EGF treatment mediates EGFR activation in ACP, which is described to promote radioresistance in vitro. ${ }^{7,23,52}$ Tumor samples $(\mathrm{n}=8)$ with and without EGF stimulation were subjected to a total dose of 12 Gy $(6 \times 2$ Gy) irradiation (Fig. 1). Overall, we
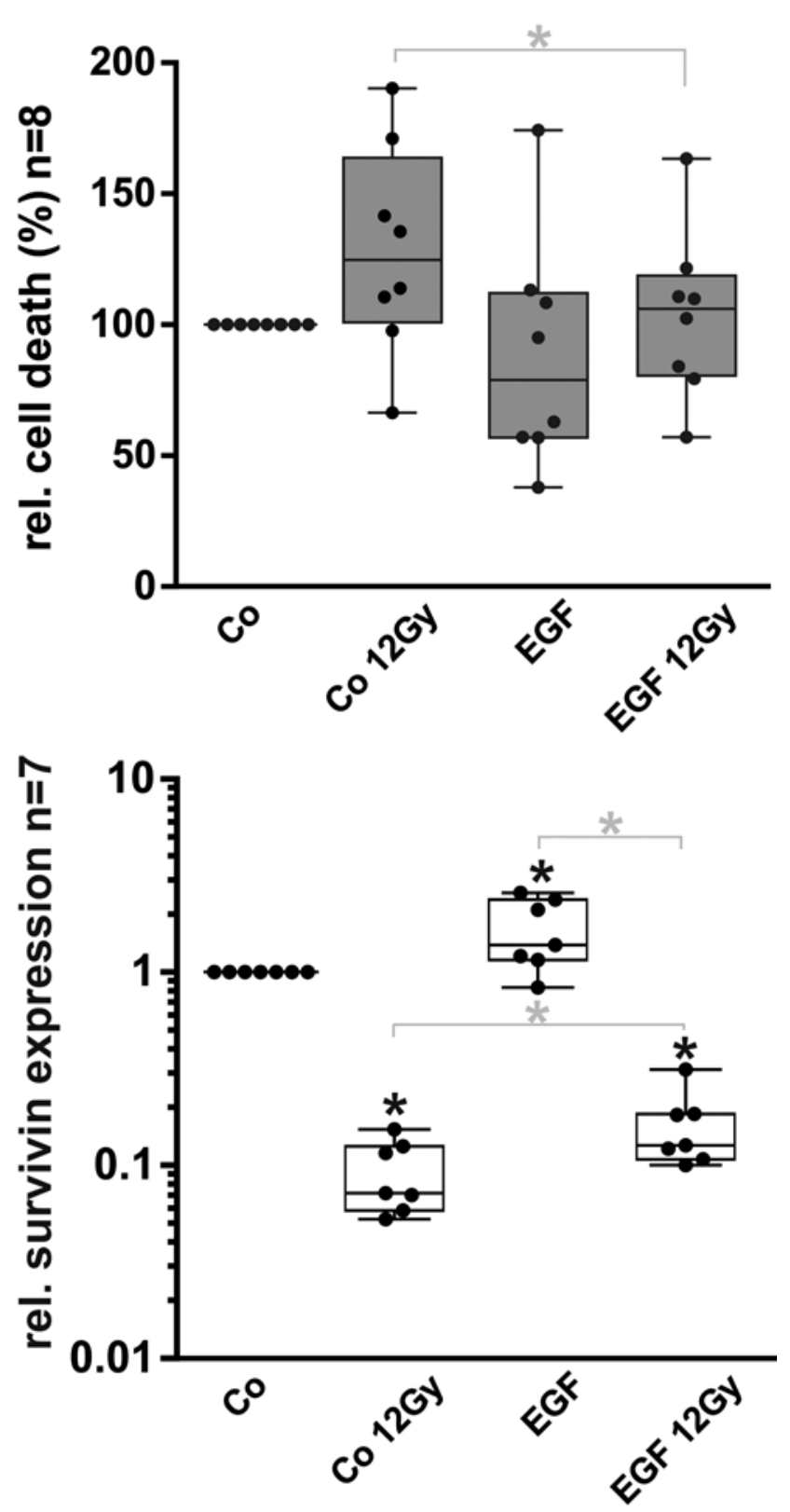

FIG. 1. EGF treatment promotes radioresistance in ACP after treatment with $12 \mathrm{~Gy}$ radiotherapy. Upper: Flow cytometry analyses (AxV/PI) of ACP cells $(n=8)$ revealed increased cell death induction after $12 \mathrm{~Gy}$ radiotherapy (Co $12 \mathrm{~Gy}$ ) relative to nonirradiated cells (Co). Treatment with EGF combined with 12 Gy (EGF 12 Gy) results in significantly lower cell death rate compared with cells that did not receive EGF stimulation (Co 12 Gy). EGF treatment only promotes cell survival, indicated by lower cell death rates. Lower: Survivin mRNA expression $(n=7)$ is enhanced by EGF stimulation but reduced after radiotherapy (12 Gy) in cells with and without EGF treatment. $\mathrm{Co}=$ mock treated; Co $12 \mathrm{~Gy}=$ mock treated + $(6 \times 2 \mathrm{~Gy}) ; \mathrm{EGF}=10 \mathrm{ng} / \mathrm{ml} \mathrm{EGF} ; \mathrm{EGF} 12 \mathrm{~Gy}=10 \mathrm{ng} / \mathrm{ml}$ $\mathrm{EGF}+(6 \times 2 \mathrm{~Gy})$. rel. $=$ relative. ${ }^{*} p \leq 0.05$.

observed a significantly lower rate of irradiation-induced cell death after EGF treatment compared with samples without EGF supplementation (Fig. 1 upper). EGF treatment only promoted cell survival relative to unstimulated ACP cells. This result confirms EGFR-induced radioresistance, supported by mRNA expression analyses of the 
pro-survival protein survivin $(n=7)$, which is enhanced after EGF treatment relative to unstimulated control cells (Fig. 1 lower). Radiotherapy notably reduced survivin expression compared with nonirradiated cells, whereas EGF treatment demonstrated a protective effect on survivin expression after irradiation compared with irradiated cells without EGF treatment (Fig. 1 lower).

\section{Survivin Expression in ACP}

Immunohistochemical staining determined prominent nuclear expression of survivin in ACP (Fig. 2). Homogenous expression throughout the tumor was detected in all analyzed samples $(n=10$; Table 1$)$. Staining intensity varied between different patients, indicating a variable endogenous level of survivin expression. The notable protein level within the tumor, but not in surrounding brain tissue or glial reactive tissue, indicates a specific role of survivin in ACP biology.

\section{Cell Death Induction in ACP After Combined Radiochemotherapy With TKI}

Radiotherapy was combined with TKI treatment to investigate a potential benefit of combined radiochemotherapy over irradiation alone. Daily treatment with chemotherapy and 2 Gy of radiation therapy twice a day for 3 consecutive days (total dose 12 Gy) was set as the experimental outline. To analyze how combined radiochemotherapy impacts cell death in primary human ACP tissue culture $(n=9)$, we performed flow cytometry analyses with $\mathrm{AxV} / \mathrm{PI}$ staining to discriminate living from dead cells (Fig. 3 upper). Radiotherapy (EGF 12 Gy) showed mild effects on cell death (median $139 \%$, mean 159\%) compared with nonirradiated samples (EGF; median $100 \%$, mean $100 \%$ ). In all samples analyzed, combined radiochemotherapy resulted in significant cell death induction. The overall impact of CUDC-101 as a single therapeutic (median $180 \%$, mean $237 \%$ ) or combined with radiotherapy (median $274 \%$, mean $299 \%$ ) was more effective regarding cell death than gefitinib (median $150 \%$, mean 156\%) or combined radiochemotherapy with gefitinib (median 191\%, mean $221 \%$ ). Treatment of different primary ACP samples demonstrated variable sensitivity of different patients to different treatment schemes (Fig. 3 upper). Overall, the statistical evaluation and comparison of different treatment schemes revealed an advantage of combined radiochemotherapy. While treatment with CUDC-101 is superior but not statistically significant compared with radiation only (EGF 12 Gy; $p=0.2031$ ), the combination of CUDC-101 and radiation (CUDC 12 Gy) exceeded radiotherapy alone in a statistically significant manner $(p=0.0039)$. The same observation applied to sole gefitinib treatment compared with radiation only (EGF 12 Gy), which resulted in a slight difference that was not statistically significant ( $p>0.9999)$, whereas combination therapy of gefitinib with 12 Gy outperformed pure radiation $(\mathrm{p}=0.0039)$.

To further investigate the impact of combined radiochemotherapy on survival-associated gene expression, we measured changes in mRNA expression by means of qRT-PCR relative to EGF-treated cells $(n=7)$. Analyzing the pro-survival protein survivin demonstrated significant
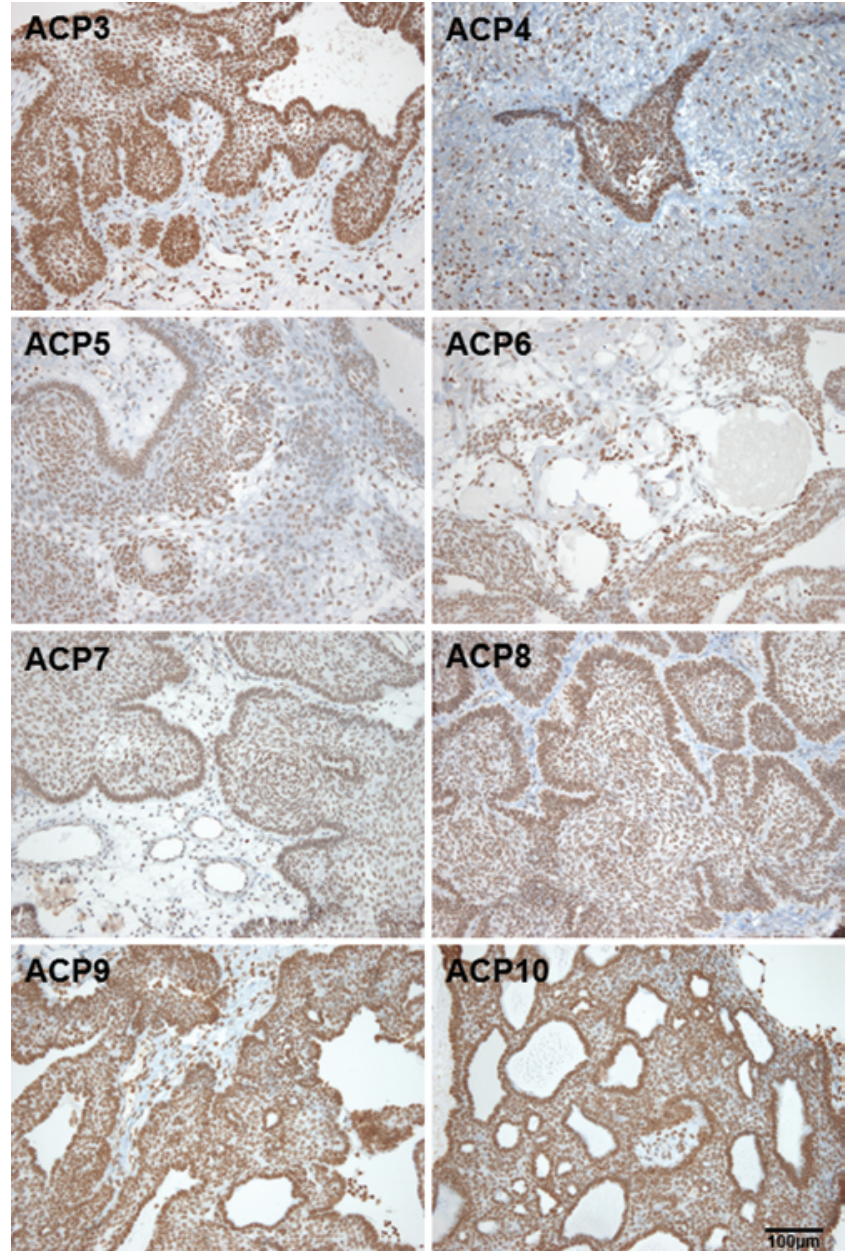

FIG. 2. Immunohistochemical analysis of the survivin expression pattern confirms its nuclear localization throughout the tumor as shown in 8 different ACP samples (ACP3-ACP10). Bar $=100 \mu \mathrm{m}$.

changes in survivin mRNA expression after radiochemotherapy (Fig. 3 lower). The addition of EGF to the cell culture medium acts as a positive regulator for survivin expression (Fig. 1 lower), whereas any therapeutic intervention resulted in a distinct reduction of survivin gene expression in vitro. Remarkably, radiotherapy with $12 \mathrm{~Gy}$ or therapy with CUDC-101 alone resulted in equivalent reduction of survivin mRNA expression. Sole treatment with gefitinib showed a significant reduction in survivin mRNA but was less effective than CUDC-101 (Fig. 3 lower).

\section{Inhibition of Survivin and the Effect on Cell Viability and Proliferation In Vitro}

Survivin mRNA expression was impaired by using siRNA in primary ACP tumor cell cultures $(n=6)$. Mocktreated (siCo) and survivin-directed siRNA (siSurvivin)treated tumor cells were analyzed 72 hours after transfection. qRT-PCR demonstrated successful reduction of survivin mRNA levels of $80 \%$ or more (Fig. 4A).

To assess the impact of survivin expression on cell survival and proliferation we compared mock-treated and siSurvivin-treated cells of different ACP cases. Transfection 


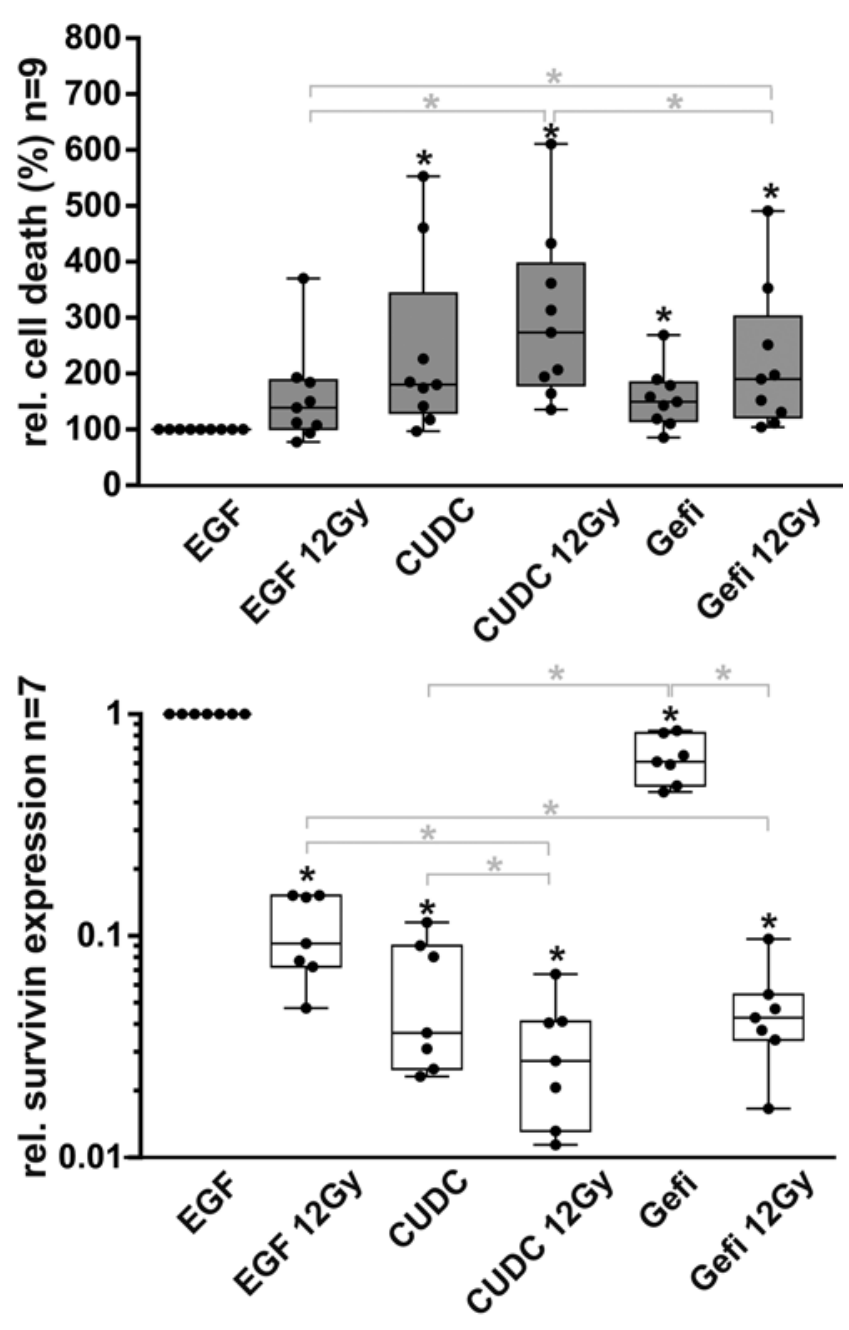

FIG. 3. Combined radiochemotherapy with TKI resulted in elevated cell death rates and reduced survivin expression in ACP. Upper: Flow cytometry analyses (AxV/PI) of ACP cells $(n=9)$ revealed increased cell death induction after radiotherapy, chemotherapy, or combined radiochemotherapy with TKI and $12 \mathrm{~Gy}$. Lower: Relative to EGF-treated cells, survivin mRNA expression was assessed in human ACP cell cultures $(n=7)$ after treatment with radio-, chemo- or combined radiochemotherapy. EGF = EGF only; EGF 12 Gy = EGF + $(6 \times 2$ Gy); CUDC = EGF + CUDC-101; CUDC 12 Gy = EGF + CUDC-101 + (6 × 2 Gy); gefitinib = EGF + gefitinib; gefitinib 12 Gy = EGF + gefitinib + (6 2 2 Gy). Gefi $=$ gefitinib. ${ }^{*} p \leq 0.05$.

was performed directly in a 96-well plate without further transferring the cells. To guarantee effective inhibition we used the same lipofectamine master mix for simultaneous large-scale transfection of cells used for assessing survivin inhibition. All cases $(n=6)$ showed an average decrease in proliferation between 5\% and 44\% (mean 30\%, $\mathrm{n}=6$; Fig. 4B). Simultaneously, cell viability was reduced by $25 \%$ after siSurvivin treatment compared with their control (siCo; Fig. 4C). Flow cytometry after survivin inhibition confirmed elevated cell death levels, compared with mocktreated controls (mean 109\%, $n=6$; Fig. 4D).

\section{Discussion}

According to the WHO classification of brain tumors
ACPs are benign lesions, although treatment can be extremely difficult. Localization of the tumor as well as microscopic invasive growth pattern can interfere with gross-total resection. Regardless of primary treatment, many craniopharyngiomas recur. To date there has been a paucity of investigation into possible targeted therapy. ACPs harbor mutations in exon 3 of the CTNNBI gene leading to constant activation of the Wnt pathway, ${ }^{24}$ which is essential during development but also in cancer pathogenesis. Wnt activation results in $\beta$-catenin accumulation in cell clusters, identified as being responsible for tumor cell migration and tumor recurrence in ACP. ${ }^{23}$ In addition, the EGFR signaling activation contributes to tumor cell migration. ${ }^{39,42,61,72}$ Various studies demonstrated cross-talk between Wnt and EGFR signaling, where canonical Wnt signaling activation, accompanied by $\beta$-catenin accumulation, resulted in activation of the EGFR or vice versa. ${ }^{27}$ After identification of the EGFR pathway as a potential therapeutic target in $\mathrm{ACP}{ }^{23}$ we hypothesized that nuclear translocation of the EGFR, predominantly in whirllike clusters, promotes radioresistance. The hypothesis of a radioresistant phenotype is further supported by the expression of markers involved in radioresistance such as nuclear $\beta$-catenin, CD133, CD44, and p21. . $26,35,36,59,69,70$

\section{Effect of Combined Radiochemotherapy With TKI in ACP on Cell Death}

Cell death analyses of primary ACP cultures via flow cytometry confirmed a protective effect of EGFR activation regarding cell death after 12 Gy radiotherapy; this result is consistent with our hypothesis that activation of EGFR mediates radioresistance. Different patient-derived ACP cases showed individual response and cell-death promoting effects of TKI treatment. The regulation of survivin expression is believed to be responsible for the observed effects and was described as a potential treatment target in other cancer studies. ${ }^{1,4,33,41}$ While activation of the EGFR by adding EGF to the cell culture medium enhanced survivin mRNA expression in ACP, gefitinib as well as CUDC-101 were identified as potent inhibitors of survivin expression, even without additional radiotherapy. This observation is particularly interesting regarding ACP treatment, because radiotherapy is detrimental to the pituitary gland and hypothalamus. Irradiation alone inhibited survivin expression in vitro but did not cause substantial cell death in this tumor, marked by a low proliferation index. Gefitinib treatment benefits from the combination with radiotherapy in terms of cell death response by survivin inhibition. A combination of radiochemotherapy with CUDC-101 also showed increased cell death response in comparison with sole treatment with the inhibitor.

All cases analyzed in this study responded to radiochemotherapy, whereas CUDC-101 demonstrated a higher overall impact. While gefitinib exclusively acts on the EGFR, CUDC-101 additionally targets HER 2 and HDACs and inhibits downstream signaling as AKT, HER3, and MET ${ }^{64}$ which are involved in resistance against single-target EGFR inhibitory therapeutics. ${ }^{38}$ Inhibition of HDACs results in growth arrest and apoptosis. ${ }^{16,22,54}$ CUDC-101 as a multitarget HDAC inhibitor should be considered for preclinical in vivo studies of patient-derived xenograft 

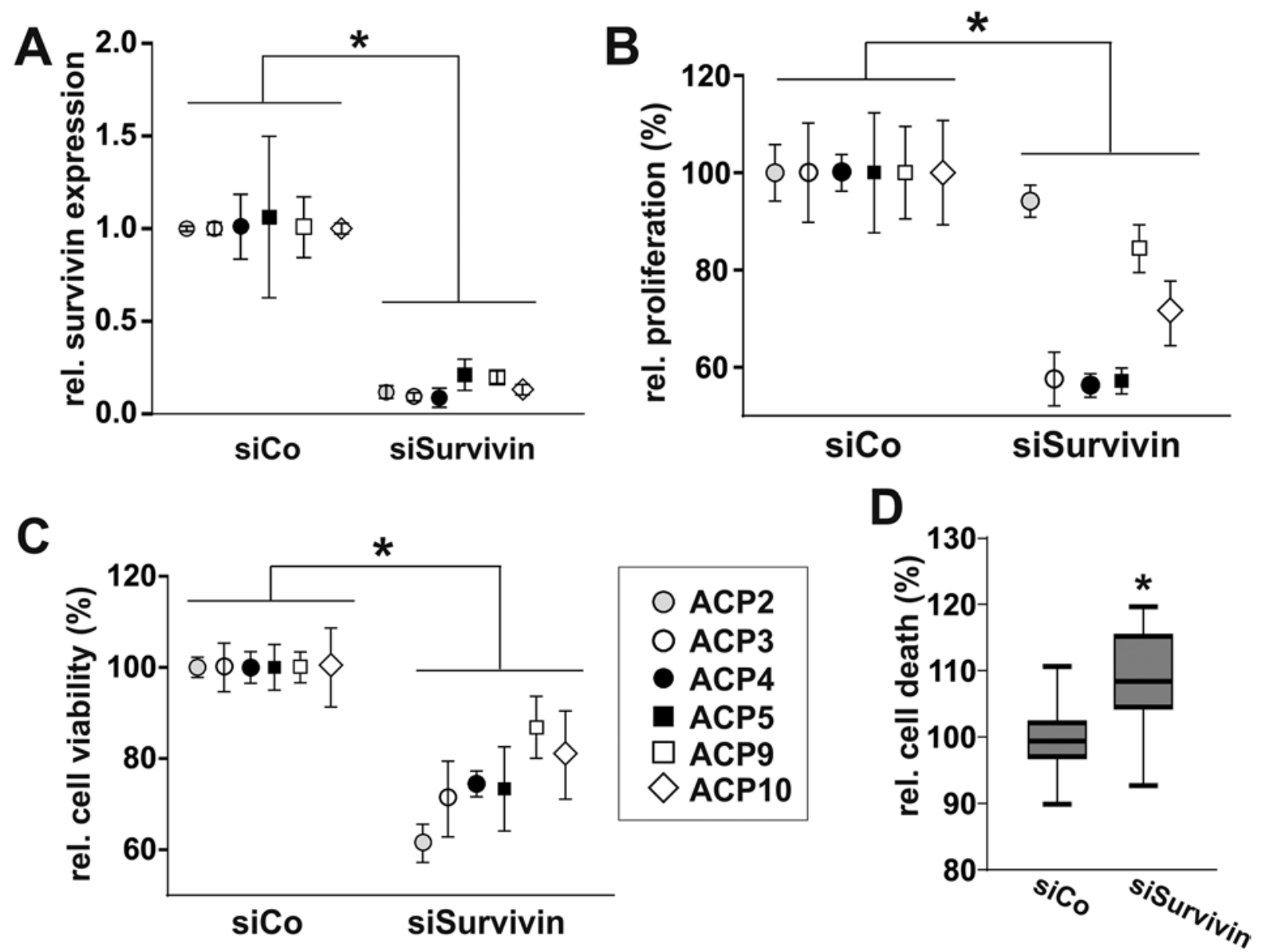

FIG. 4. Reduced cell viability and proliferation after survivin inhibition by siRNA $(n=6)$. A: ACP primary cells were transfected with siRNA survivin (siSurvivin) to inhibit survivin mRNA levels or mock treated with control siRNA (siCo). Successful survivin mRNA downregulation of $80 \%$ or more was confirmed by qRT-PCR. B and C: The proliferation rate measured by BrdU uptake was diminished $30 \%$ on average compared with mock-treated cells (B), whereas an average reduction of $25 \%$ in cell viability was measured in an MTT assay (C). D: AxV/PI staining in flow cytometry analyses confirmed elevated cell death levels after survivin inhibition. ${ }^{*} p \leq 0.05$.

models to complement or improve radiotherapy. The broad spectrum of inhibitory effects of CUDC-101 will have to be considered in clinical use, regarding potential side effects. A clinical Phase I study demonstrated stable disease in gastric cancer after systemic treatment with CUDC-101 with mild transient side effects only. ${ }^{63}$

\section{Inhibition of Survivin is a Promising Target in ACP Treatment}

Irradiation with gamma x-rays induces DNA damage, detected during DNA replication, leading to cell cycle arrest and cell death if DNA repair mechanisms fail. Survivin enhances DNA repair, shown in survivin overexpressing glioblastoma and squamous epithelial cell carcinoma. ${ }^{29,57}$ The inhibition of survivin expression could explain the underlying mechanism of cell death induction after TKI treatment and is therefore a promising target to improve treatment protocols involving radiotherapy in ACP. Survivin knockdown using siRNA showed a remarkable impact on cell viability in ACP that results from a combined effect on decreased cell proliferation as well as enhanced cell death induction. Consistently, inhibition of survivin was promising in HeLa cells,${ }^{64}$ melanoma, ${ }^{44}$ prostate carcinoma, ${ }^{53}$ pancreatic carcinoma, ${ }^{30}$ and endometrial cancer, ${ }^{2}$ where lower expression levels induced caspase-dependent apoptosis, reduced proliferation, delayed tumor growth, and enhanced sensitivity to treatment with cytotoxic agents and radiotherapy. Survivin protein is stabilized by blocked ubiquitination in pancreatic cells mediated through EGF, and the Raf1/-MEK-/ERK signaling ${ }^{68}$ and degradation could be blocked by this mechanism in ACP as well.

A previous study analyzed survivin expression in craniopharyngioma immunohistochemically, where it was considered as a prognostic marker for recurrent disease. ${ }^{73}$ Nuclear localization such as we observed in ACP is described to be a negative prognostic factor in non-small cell lung cancer, ${ }^{20}$ laryngeal cancer, ${ }^{43}$ and urothelial carcinoma,${ }^{34}$ where it was associated with invasion, progression, and worse prognosis as well as higher recurrence rates. In contrast, colon carcinoma demonstrated better outcome if survivin was present in the nucleus. ${ }^{56}$ In astrocytoma, simultaneous nuclear and cytoplasmic expression was con- 
firmed as a prognostic factor. ${ }^{60}$ The function of survivin is dependent on its subcellular localization. While nuclear protein acts as a cell cycle regulator ${ }^{44}$ and promotes repair of double strand breaks ${ }^{57}$ involved in radioresistance, cytoplasmic but also mitochondrial survivin adds to antiapoptotic signaling. Besides wild-type survivin, the different splice variants DeltaEx3, 2B [72], 3B, and 2alpha ${ }^{10}$ result in transcript domains with different functions. For instance, deltaEx3 is exclusively nuclear as the missing exon 3 encodes for the nuclear export signal. ${ }^{47}$

\section{Conclusions}

The present study shows evidence for reduced radiosensitivity in EGFR-activated cells and generated mandatory data for future in vivo studies using EGFR inhibitors (gefitinib or CUDC-101) in ACP. Combined radiochemotherapy with TKI in vitro demonstrates a beneficial effect regarding cell death induction by suppressing the expression of the pro-survival protein survivin. These observations will now be validated in a translational treatment approach in a patient-derived xenograft model for human ACP.18,65 We believe that results from the in vivo study could be quickly transferred into clinical management and benefit patients with ACPs.

\section{Acknowledgments}

This study was funded by the Doktor Robert Pfleger-Stiftung in Bamberg (R.B. and A.H.) and the Deutsche Forschungsgemeinschaft (R.B.; grant no. BU 2878/2-1). We would like to thank Tajana Jungbauer, Diana Maron, and Birte Rings for their excellent support and technical assistance. We appreciate the contribution of Jonas Granzow, who supported this project experimentally.

\section{References}

1. Adida C, Berrebi D, Peuchmaur M, Reyes-Mugica M, Altieri DC: Anti-apoptosis gene, survivin, and prognosis of neuroblastoma. Lancet 351:882-883, 1998

2. Ai Z, Yin L, Zhou X, Zhu Y, Zhu D, Yu Y, et al: Inhibition of survivin reduces cell proliferation and induces apoptosis in human endometrial cancer. Cancer 107:746-756, 2006

3. Altieri DC: Targeting survivin in cancer. Cancer Lett 332:225-228, 2013

4. Ambrosini G, Adida C, Altieri DC: A novel anti-apoptosis gene, survivin, expressed in cancer and lymphoma. Nat Med 3:917-921, 1997

5. Asami K, Atagi S: Epidermal growth factor receptor tyrosine kinase inhibitors for non-small cell lung cancer. World J Clin Oncol 5:646-659, 2014

6. Bao S, Wu Q, McLendon RE, Hao Y, Shi Q, Hjelmeland $\mathrm{AB}$, et al: Glioma stem cells promote radioresistance by preferential activation of the DNA damage response. Nature 444:756-760, 2006

7. Brand TM, Iida M, Luthar N, Starr MM, Huppert EJ, Wheeler DL: Nuclear EGFR as a molecular target in cancer. Radiother Oncol 108:370-377, 2013

8. Buchfelder M, Schlaffer SM, Lin F, Kleindienst A: Surgery for craniopharyngioma. Pituitary 16:18-25, 2013

9. Buslei R, Hölsken A, Hofmann B, Kreutzer J, Siebzehnrubl F, Hans V, et al: Nuclear $\beta$-catenin accumulation associates with epithelial morphogenesis in craniopharyngiomas. Acta Neuropathol 113:585-590, 2007

10. Caldas H, Honsey LE, Altura RA: Survivin $2 \alpha$ : a novel Survivin splice variant expressed in human malignancies. Mol Cancer 4:11, 2005
11. Chakravarti A, Dicker A, Mehta M: The contribution of epidermal growth factor receptor (EGFR) signaling pathway to radioresistance in human gliomas: a review of preclinical and correlative clinical data. Int J Radiat Oncol Biol Phys 58:927-931, 2004

12. Darzynkiewicz Z, Juan G, Li X, Gorczyca W, Murakami T, Traganos F: Cytometry in cell necrobiology: analysis of apoptosis and accidental cell death (necrosis). Cytometry 27:1-20, 1997

13. Dong Q, Sharma S, Liu H, Chen L, Gu B, Sun X, et al: HDAC inhibitors reverse acquired radio resistance of KYSE150R esophageal carcinoma cells by modulating Bmi-1 expression. Toxicol Lett 224:121-129, 2014

14. Erfurth EM, Holmer H, Fjalldal SB: Mortality and morbidity in adult craniopharyngioma. Pituitary 16:46-55, 2013

15. Fahlbusch R, Honegger J, Paulus W, Huk W, Buchfelder M: Surgical treatment of craniopharyngiomas: experience with 168 patients. J Neurosurg 90:237-250, 1999

16. Finzer P, Kuntzen C, Soto U, zur Hausen H, Rösl F: Inhibitors of histone deacetylase arrest cell cycle and induce apoptosis in cervical carcinoma cells circumventing human papillomavirus oncogene expression. Oncogene 20:4768-4776, 2001

17. Geoerger B, Gaspar N, Opolon P, Morizet J, Devanz P, Lecluse Y, et al: EGFR tyrosine kinase inhibition radiosensitizes and induces apoptosis in malignant glioma and childhood ependymoma xenografts. Int J Cancer 123:209-216, 2008

18. Hartmann J, Wölfelschneider J, Stache C, Buslei R, Derer A, Schwarz M, et al: Novel technique for high-precision stereotactic irradiation of mouse brains. Strahlenther Onkol [epub ahead of print], 2016

19. Hau E, Shen H, Clark C, Graham PH, Koh ES, L McDonald $\mathrm{K}$ : The evolving roles and controversies of radiotherapy in the treatment of glioblastoma. J Med Radiat Sci 63:114-123, 2016

20. He L, Hou M, Zhang J, Xu N, Chen P: [Subcellular localization of survivin in non-small cell lung cancer.] Ai Zheng 28:955-960, 2009 (Chinese)

21. Hölsken A, Buchfelder M, Fahlbusch R, Blümcke I, Buslei R: Tumour cell migration in adamantinomatous craniopharyngiomas is promoted by activated Wnt-signalling. Acta Neuropathol 119:631-639, 2010

22. Hölsken A, Eyüpoglu IY, Lueders M, Tränkle C, Dieckmann D, Buslei R, et al: Ex vivo therapy of malignant melanomas transplanted into organotypic brain slice cultures using inhibitors of histone deacetylases. Acta Neuropathol 112:205215,2006

23. Hölsken A, Gebhardt M, Buchfelder M, Fahlbusch R, Blümcke I, Buslei R: EGFR signaling regulates tumor cell migration in craniopharyngiomas. Clin Cancer Res 17:4367-4377, 2011

24. Hölsken A, Kreutzer J, Hofmann BM, Hans V, Oppel F, Buchfelder M, et al: Target gene activation of the Wnt signaling pathway in nuclear $\beta$-catenin accumulating cells of adamantinomatous craniopharyngiomas. Brain Pathol 19:357-364, 2009

25. Hölsken A, Sill M, Merkle J, Schweizer L, Buchfelder M, Flitsch J, et al: Adamantinomatous and papillary craniopharyngiomas are characterized by distinct epigenomic as well as mutational and transcriptomic profiles. Acta Neuropathol Commun 4:20, 2016

26. Hölsken A, Stache C, Schlaffer SM, Flitsch J, Fahlbusch R, Buchfelder M, et al: Adamantinomatous craniopharyngiomas express tumor stem cell markers in cells with activated Wnt signaling: further evidence for the existence of a tumor stem cell niche? Pituitary 17:546-556, 2014

27. Hu T, Li C: Convergence between Wnt- $\beta$-catenin and EGFR signaling in cancer. Mol Cancer 9:236, 2010 
28. Iannalfi A, Fragkandrea I, Brock J, Saran F: Radiotherapy in craniopharyngiomas. Clin Oncol (R Coll Radiol) 25:654667,2013

29. Jiang G, Ren B, Xu L, Song S, Zhu C, Ye F: Survivin may enhance DNA double-strand break repair capability by up-regulating Ku70 in human KB cells. Anticancer Res 29:223-228, 2009

30. Kami K, Doi R, Koizumi M, Toyoda E, Mori T, Ito D, et al: Downregulation of survivin by siRNA diminishes radioresistance of pancreatic cancer cells. Surgery 138:299-305, 2005

31. Karavitaki N: Management of craniopharyngiomas. J Endocrinol Invest 37:219-228, 2014

32. Karavitaki N, Cudlip S, Adams CB, Wass JA: Craniopharyngiomas. Endocr Rev 27:371-397, 2006

33. Kawasaki H, Altieri DC, Lu CD, Toyoda M, Tenjo T, Tanigawa N: Inhibition of apoptosis by survivin predicts shorter survival rates in colorectal cancer. Cancer Res 58:50715074, 1998

34. Kitamura H, Torigoe T, Hirohashi Y, Asanuma H, Inoue R, Nishida S, et al: Nuclear, but not cytoplasmic, localization of survivin as a negative prognostic factor for survival in upper urinary tract urothelial carcinoma. Virchows Arch 462:101107, 2013

35. Kokunai T, Tamaki N: Relationship between expression of p21WAF1/CIP1 and radioresistance in human gliomas. Jpn J Cancer Res 90:638-646, 1999

36. Kokunai T, Urui S, Tomita H, Tamaki N: Overcoming of radioresistance in human gliomas by $\mathrm{p} 21 \mathrm{WAF} 1 / \mathrm{CIP} 1$ antisense oligonucleotide. J Neurooncol 51:111-119, 2001

37. Koopman G, Reutelingsperger CP, Kuijten GA, Keehnen RM, Pals ST, van Oers MH: Annexin V for flow cytometric detection of phosphatidylserine expression on B cells undergoing apoptosis. Blood 84:1415-1420, 1994

38. Lai CJ, Bao R, Tao X, Wang J, Atoyan R, Qu H, et al: CUDC101 , a multitargeted inhibitor of histone deacetylase, epidermal growth factor receptor, and human epidermal growth factor receptor 2 , exerts potent anticancer activity. Cancer Res 70:3647-3656, 2010

39. Lee CH, Hung HW, Hung PH, Shieh YS: Epidermal growth factor receptor regulates $\beta$-catenin location, stability, and transcriptional activity in oral cancer. Mol Cancer 9:64, 2010

40. Louis DN, Ohgaki H, Wiestler OD, Cavenee WK: WHO Classification of Tumours of the Central Nervous System, Revised, ed 4. Lyon, France: International Agency for Research on Cancer, 2016

41. Lu CD, Altieri DC, Tanigawa N: Expression of a novel antiapoptosis gene, survivin, correlated with tumor cell apoptosis and p53 accumulation in gastric carcinomas. Cancer Res 58:1808-1812, 1998

42. Lu Z, Ghosh S, Wang Z, Hunter T: Downregulation of caveolin-1 function by EGF leads to the loss of E-cadherin, increased transcriptional activity of $\beta$-catenin, and enhanced tumor cell invasion. Cancer Cell 4:499-515, 2003

43. Marioni G, Agostini M, Bedin C, Blandamura S, Stellini E, Favero G, et al: Survivin and laryngeal carcinoma prognosis: nuclear localization and expression of splice variants. Histopathology 61:247-256, 2012

44. McKenzie JA, Grossman D: Role of the apoptotic and mitotic regulator survivin in melanoma. Anticancer Res 32:397404, 2012

45. Mobahat M, Narendran A, Riabowol K: Survivin as a preferential target for cancer therapy. Int J Mol Sci 15:2494-2516, 2014

46. Mortini P, Gagliardi F, Boari N, Losa M: Surgical strategies and modern therapeutic options in the treatment of craniopharyngiomas. Crit Rev Oncol Hematol 88:514-529, 2013

47. Mull AN, Klar A, Navara CS: Differential localization and high expression of SURVIVIN splice variants in human em- bryonic stem cells but not in differentiated cells implicate a role for SURVIVIN in pluripotency. Stem Cell Res (Amst) 12:539-549, 2014

48. Müller HL: Craniopharyngioma. Endocr Rev 35:513-543, 2014

49. Nicoletti I, Migliorati G, Pagliacci MC, Grignani F, Riccardi $\mathrm{C}$ : A rapid and simple method for measuring thymocyte apoptosis by propidium iodide staining and flow cytometry. $\mathbf{J}$ Immunol Methods 139:271-279, 1991

50. O'Connor DS, Grossman D, Plescia J, Li F, Zhang H, Villa A, et al: Regulation of apoptosis at cell division by $\mathrm{p} 34 \mathrm{cdc} 2$ phosphorylation of survivin. Proc Natl Acad Sci U S A 97:13103-13107, 2000

51. Okamoto K, Okamoto I, Okamoto W, Tanaka K, Takezawa $\mathrm{K}$, Kuwata K, et al: Role of survivin in EGFR inhibitorinduced apoptosis in non-small cell lung cancers positive for EGFR mutations. Cancer Res 70:10402-10410, 2010

52. O'Rourke DM, Kao GD, Singh N, Park BW, Muschel RJ, Wu $\mathrm{CJ}$, et al: Conversion of a radioresistant phenotype to a more sensitive one by disabling erbB receptor signaling in human cancer cells. Proc Natl Acad Sci U S A 95:10842-10847, 1998

53. Paduano F, Villa R, Pennati M, Folini M, Binda M, Daidone MG, et al: Silencing of survivin gene by small interfering RNAs produces supra-additive growth suppression in combination with 17-allylamino-17-demethoxygeldanamycin in human prostate cancer cells. Mol Cancer Ther 5:179-186, 2006

54. Pennati M, Binda M, Colella G, Zoppe' M, Folini M, Vignati $\mathrm{S}$, et al: Ribozyme-mediated inhibition of survivin expression increases spontaneous and drug-induced apoptosis and decreases the tumorigenic potential of human prostate cancer cells. Oncogene 23:386-394, 2004

55. Pollack IF, Stewart CF, Kocak M, Poussaint TY, Broniscer A, Banerjee A, et al: A phase II study of gefitinib and irradiation in children with newly diagnosed brainstem gliomas: a report from the Pediatric Brain Tumor Consortium. Neuro Oncol 13:290-297, 2011

56. Qi G, Tuncel H, Aoki E, Tanaka S, Oka S, Kaneko I, et al: Intracellular localization of survivin determines biological behavior in colorectal cancer. Oncol Rep 22:557-562, 2009

57. Reichert S, Rödel C, Mirsch J, Harter PN, Tomicic MT, Mittelbronn M, et al: Survivin inhibition and DNA double-strand break repair: a molecular mechanism to overcome radioresistance in glioblastoma. Radiother Oncol 101:51-58, 2011

58. Rödel C, Haas J, Groth A, Grabenbauer GG, Sauer R, Rödel F: Spontaneous and radiation-induced apoptosis in colorectal carcinoma cells with different intrinsic radiosensitivities: survivin as a radioresistance factor. Int J Radiat Oncol Biol Phys 55:1341-1347, 2003

59. Sahlberg SH, Spiegelberg D, Glimelius B, Stenerlöw B, Nestor M: Evaluation of cancer stem cell markers CD133, CD44, CD24: association with AKT isoforms and radiation resistance in colon cancer cells. PLoS One 9:e94621, 2014

60. Saito T, Arifin MT, Hama S, Kajiwara Y, Sugiyama K, Yamasaki F, et al: Survivin subcellular localization in high-grade astrocytomas: simultaneous expression in both nucleus and cytoplasm is negative prognostic marker. J Neurooncol 82:193-198, 2007

61. Schroeder JA, Adriance MC, McConnell EJ, Thompson MC, Pockaj B, Gendler SJ: ErbB- $\beta$-catenin complexes are associated with human infiltrating ductal breast and murine mammary tumor virus (MMTV)-Wnt-1 and MMTV-c-Neu transgenic carcinomas. J Biol Chem 277:22692-22698, 2002

62. Schweizer L, Capper D, Hölsken A, Fahlbusch R, Flitsch J, Buchfelder M, et al: BRAF V600E analysis for the differentiation of papillary craniopharyngiomas and Rathke's cleft cysts. Neuropathol Appl Neurobiol 41:733-742, 2015

63. Shimizu T, LoRusso PM, Papadopoulos KP, Patnaik A, Beeram M, Smith LS, et al: Phase I first-in-human study of 
CUDC-101, a multitargeted inhibitor of HDACs, EGFR, and HER 2 in patients with advanced solid tumors. Clin Cancer Res 20:5032-5040, 2014

64. Song H, Xin XY, Xiao F, Wang DT, Yue QH, Han X: Survivin gene RNA interference inhibits proliferation, induces apoptosis, and enhances radiosensitivity in HeLa cells. Eur J Obstet Gynecol Reprod Biol 136:83-89, 2008

65. Stache C, Hölsken A, Schlaffer SM, Hess A, Metzler M, Frey $\mathrm{B}$, et al: Insights into the infiltrative behavior of adamantinomatous craniopharyngioma in a new xenotransplant mouse model. Brain Pathol 25:1-10, 2015

66. Ulfarsson E, Karström A, Yin S, Girnita A, Vasilcanu D, Thoren M, et al: Expression and growth dependency of the insulin-like growth factor I receptor in craniopharyngioma cells: a novel therapeutic approach. Clin Cancer Res 11:4674-4680, 2005

67. Vermes I, Haanen C, Steffens-Nakken H, Reutelingsperger $\mathrm{C}$ : A novel assay for apoptosis. Flow cytometric detection of phosphatidylserine expression on early apoptotic cells using fluorescein labelled Annexin V. J Immunol Methods 184:39-51, 1995

68. Wang H, Gambosova K, Cooper ZA, Holloway MP, Kassai A, Izquierdo D, et al: EGF regulates survivin stability through the Raf-1/ERK pathway in insulin-secreting pancreatic $\beta$-cells. BMC Mol Biol 11:66, 2010

69. Wang L, Zhang XM, Li Z, Liu XJ, Chai J, Zhang GY, et al: Overexpression of nuclear $\beta$-catenin in rectal adenocarcinoma is associated with radioresistance. World J Gastroenterol 19:6876-6882, 2013

70. Woodward WA, Chen MS, Behbod F, Alfaro MP, Buchholz TA, Rosen JM: WNT/ $\beta$-catenin mediates radiation resistance of mouse mammary progenitor cells. Proc Natl Acad Sci U S A 104:618-623, 2007
71. Xu W, Ngo L, Perez G, Dokmanovic M, Marks PA: Intrinsic apoptotic and thioredoxin pathways in human prostate cancer cell response to histone deacetylase inhibitor. Proc Natl Acad Sci U S A 103:15540-15545, 2006

72. Yu WH, Woessner JF Jr, McNeish JD, Stamenkovic I: CD44 anchors the assembly of matrilysin/MMP-7 with heparinbinding epidermal growth factor precursor and ErbB4 and regulates female reproductive organ remodeling. Genes Dev 16:307-323, 2002

73. Zhu J, You C: Craniopharyngioma: survivin expression and ultrastructure. Oncol Lett 9:75-80, 2015

\section{Disclosures}

The authors report no conflict of interest concerning the materials or methods used in this study or the findings specified in this paper.

\section{Author Contributions}

Conception and design: Hölsken, Stache, Buslei. Acquisition of data: Hölsken, Stache, Bils. Analysis and interpretation of data: Hölsken, Stache, Bils. Drafting the article: Hölsken, Stache. Critically revising the article: Fahlbusch, Flitsch, Buchfelder, Stefanits, Czech, Gaipl, Frey, Buslei. Reviewed submitted version of manuscript: Stache. Administrative/technical/material support: Fahlbusch, Flitsch, Buchfelder, Stefanits, Czech, Gaipl, Frey.

\section{Correspondence}

Annett Hölsken, Department of Neuropathology, Universitätsklinikum Erlangen, Schwabachanlage 6, Erlangen 91054, Germany. email: annett.hoelsken@uk-erlangen.de. 